\title{
Resources of Educational and Healthcare Industries and Population Welfare: Comparative Analysis in Post-socialist and OECD Countries
}

\author{
LYUDMYILA SYNYAYEVA \\ Department of Accounting and Auditing \\ Dmytro Motornyi Tavria State Agrotechnological University: \\ Melitopol, 18, B. Khmelnytsky Ave. \\ Melitopol, UKRAINE \\ ludsin2017@ukr.net \\ DENYS VERBA \\ Department of Economic Theory \\ Kyiv National Economics University named after Vadym Hetman: \\ Kiev, 54/1 Prospect Peremogy \\ Kyiv, UKRAINE \\ ANGELINA YARCHUK \\ Department of Accounting and Auditing \\ Dmytro Motornyi Tavria State Agrotechnological University: Melitopol \\ Melitopol, 18, B. Khmelnytsky Ave. \\ Melitopol, UKRAINE \\ IRYNA VERKHOVOD \\ Department of Economics and Hotel and Restaurant Business \\ Bohdan Khmelnitskiy Melitopol State Pedagogical University \\ Melitopol, Hetmanska St, 20, \\ Melitopol, UKRAINE \\ DENYS ALEKSANDROV \\ Department of Philosophy \\ Bohdan Khmelnitskiy Melitopol State Pedagogical University \\ Melitopol, Hetmanska St, 20, \\ Melitopol, UKRAINE
}

\begin{abstract}
This article is devoted to defining Ukraine's position among 28 OECD countries relative to the averaged line of connection between resources of the social sphere and the society achievements in terms of human development index. Such positioning allows us to obtain a comparative assessment of the effectiveness of usage resource, directed to funding the education and healthcare by OECD countries and Ukraine. The model that expresses the HDI dependence on three main groups of factors was used. First - the amount of education and healthcare resources (evaluated by private and public spending on education and healthcare per capita). The second - is the way of rationing the population's access to these industries products (evaluated by coefficients of inequality of life expectancy and inequality in education). The third - is the indicators, displaying the efficiency of resources using within the industry (estimated as a result of modeling). Our results have confirmed that the resources, allocated to the public sector of education have the most significant impact on HDI size and this indicator is more dependent on the amount of social sphere resources in post-socialist countries than in "old" OECD members. The actual level of HDI in Ukraine is lower than estimated by model-averaged for countries, included in the sample. This means that Ukraine uses resources of its social sphere with lower efficiency than observed as average for countries, included in the sample.
\end{abstract}


Such results allow us to obtain assessment which part of restrictions and problem experienced by national social spheres is caused by the scarcity of resources, divided to social sphere funding, and

which - by imperfections, inherent to the regulative institutions of the social sphere.

Such results may

serve as a significant precondition of social policy development, especially for post-soviet countries.

Key-Words: resource endowment, social sphere, HDI factors, social efficiency.

Received: August 10, 2020. Revised: February 4, 2021. Accepted: March 1, 2021.

Published: March 8, 2021.

\section{Introduction}

The growth of the population welfare is largely ensured and is expressed through the results, gained by the two leading industries of the social sphere - education and healthcare. At the same time, the nature of the connection between these sectors and the economy is critical to the model of reproduction of the population life quality. Developed countries are distinguished by the fact that their high economic efficiency provides a powerful resource base for the development of the educational and healthcare industries, and their results, in turn, ensure the leading source for competitive advantages of these countries in global markets - high availability of skilled personnel for high-tech types of economic activity. It is precisely this unity of "powerful resources of social sphere - advantages in quality of human capital - high revenues from globalized economic activity - additional resources for the social sphere" that provides the reproduction of high standard of living in the developed countries (see, for example [1]). The model of lagging by the quality of life has also been clearly formed: "low incomes deficient financing of social sphere specialization in low-income economic activities - chronic shortage of resources for social sphere" [2;3;4]. And the tendency to increase the inequality between countries (widening of the gap between poor and rich countries) may be interpreted as a manifestation of the cumulative nature of such model of reproduction: poor countries are doomed to poverty reproduction, until they overcome the cycle "insufficient resources of social sphere - specialization in low-income economic activities».

However, if we move from the general trends to the scenarios of the development, used by the different national economies, we can see an extremely diverse set of possible ways to reduce the backlog from developed counties, both in terms of per capita income and in quality of life (the most universal measure of which is given by HDI). Thus, according to reports on human development [5], there is a convergence of countries by quality of life against divergence of incomes per capita therefore, resource constraint of the social sphere is not insurmountable, countries can improve the quality of human capital by overcoming the problem of a relatively low per capita GDP. For Ukraine, an understanding the regularities, inherent to the interaction between the economy and the social sphere is absolutely necessary for the transition from the model of "reproduction of poverty" to the model of "mutually supportive development of the economy and social sphere".

The experience of post-socialist countries, which managed to ensure the dynamic growth of both: income per capita and the quality of life is particularly valuable for Ukraine in this context. In this article, we try only to define position of Ukraine among 28 OECD countries relative to the averaged line of connection between resources of social sphere and the achievements of society in terms of human development index.

This purpose stipulates two main tasks of this article. First is formalization of connection, between resource endowment of social sphere and the index of human development, observed for OECD countries: both, post-socialist and 
developed. The second is to define Ukrainian position relative to this trend. More detailed researching countries' deviation from averaged trend shell allows clarify the causes, which limit improving of the life quality: is it lack of social sphere resources, or the disadvantages of national institutes that regulate using of such resources.

\section{Problem Formulation}

\subsection{Literature review}

Problems of interaction between resource provision of the social sphere and the population life quality are investigated in many contexts. In particular, in the context of the study the models of national progress, the possibilities to overcome poverty and the role of social efficiency in using resources of social sphere to explain the differentiation of economic growth by country $[6 ; 7 ; 8]$.

At the same time, education, health-care, economic growth, and the quality of institutions are traditionally linked in the general vision, in the theoretical substantiation of publications, but in the process of finding an adequate mathematical tools for formalizing connections, authors usually has focused on a separate aspect of complex interaction between mentioned parameters $[9 ; 10]$.

We can distinguish three broad areas of research that differ by the approaches to the explaining consequences causing by changes in the scale of resource provision and the parameters of the functioning of education and health-care.

The first direction considers the macroeconomic consequences, most of its work are devoted to connection between amount and structure of educational and health-care spending and rate of economic growth.

The most general models include the operational characteristics of the educational and health-care industries, as factors of the economic growth rates. For example, in the Park model, the direct and indirect costs of education, expressed as a share of GDP, are taken into account as factors of the rate of economic growth [11]. In [12] the share of the population aged 12 to 17 years old, covered by secondary school education and the proportion of students among the able-bodied population aged 15-19 were used for valuation of human capital stock, accumulated by national economy. And to assess the contribution of human capital in the growth of value added the increase in salaries generated by exceeding the average wage over the minimum (the latter was considered as income not related to human capital).

Separately, in the first direction of research, we tend to highlight works where the influence of education is evaluated indirectly, through the quality of institutions, or the growth of labor productivity due to the structural changes in the economy, which lead to an increase in the average educational level of the workforce. For example, in the work [13], the quality of institutions, which is determined, in particular, by the resource provision of education, determines which type of activity will be more profitable: type aimed at finding rent from the artificial limitation of production, or type aimed at its expansion, with the using of scientific and technological progress. The connection between education and economic efficiency, which is mediated by the quality of institutions, is also studied in $[14 ; 15 ; 16]$.

For our study, the thesis of the indissolubility of the link between growth of the average educational level and the advancement of the economy on the stairs of the technological level of national production has fundamental importance: the increase in the share of hightech types of economic activity in the national product is inextricably correlated with the growth of the average educational level of the population [17].

The second direction of researches combines works that involves clarifying not only the general impact on the economy, but also the distribution of the positive effects caused by the educational and health-care sectors among groups of the population and sectors of the economy. Also, the distribution of burden, caused by the allocating resources for additional funding educational and health-care sectors is researched within this direction. For example, D. Behabib and M. Spiegel pay attention to the 
distinction between private and public benefits of education: fluctuations in the average length of school-to-country education do not explain the fluctuations of average income per person, although they affect the differentiation of countries by rates of economic growth [18, p. 94].

Works of the third direction emphasizes the absence of a direct connection between the increase of social sectors resource endowment and the social benefits, generated by education and health-care. Thus, E.Ganousek draws attention to the gap between the additional costs of education (and even the improvement of instrumental indicators, such as the ratio of the number of teachers to students number) and the growth of the society benefits, gained from education [19]. A number of studies reveal a gender gap in accessibility as well as in the effectiveness of education [20], and a large group of studies focus on obstacles that may prevent a society from fully exploiting the potential of welfare growth, given by increasing financial capabilities of the budget and individuals $[21 ; 22 ; 23 ; 24 ; 25]$.

\subsection{Research purpose}

This very important principle (the existence of a complex system, which mediates the influence of additional resources, allocated to education and healthcare on the social benefits) was the starting point and the basic provisions of our study: the clarification of the nature of Ukrainian problems, through the comparative characteristic of the connection "resources outcomes of social sphere" in Ukraine and other post-socialist and developed countries has become the main challenge of our work.

\section{Problem Solution}

\subsection{Methods and approaches}

Initial hypothesis of our work may be formulated as follows. The firstly, there is a certain functional connection between the volume of resources that society allocates for education and health-care and the achievements of such a society in the population life quality. Secondly, there is a complex and specific for each country system of factors that mediate this connection. This system includes, in particular, the structure of the social sphere resources distribution (first of all, between industries and between the private and public sectors in each of them). Also, the characteristics of regulatory institutes, regulating the using of resources in each sector of the social sphere (for example, mechanisms for stimulating teachers and doctors, forms of financial reporting of institutions, mechanisms for protecting the rights of their services consumers, etc.).

To construct the model, we proceeded from the fact that the social outcomes gained by the education and healthcare are dependent on three groups of fundamental factors.

Firstly, the volume of resources (scale of funding). It is clear that with all else being equal, the larger volumes of financial resources that society directs to the needs of any branches, in particular education and healthcare, create the preconditions for the best outcomes, gained by social due to these industries. Since, as the social outcomes of the functioning of education and healthcare, we will consider not operational goals (number of teachers to number of pupil ratio, number of hospital beds etc.), but direct characteristics of the population life quality (life expectancy), then the amount of funding should be taken into account per capita.

Second, the way of rationing the population's access to the products of these industries. High inequality of access (regardless of how it is ensured - by price factor, or verification procedures for confirmation the access right to educational and healthcare programs) means that a significant share of the population actually receives significantly lower level of availability goods and services, than may be evaluated by average (per capita) level of the industries financing. Since the targets do not depend on the best achievements in medicine or education, which can only be used by the selected, but on the level of goods available for the ordinary individual, we will consider the increasing inequalities of access to education and healthcare as a factor, which leads to the deterioration of the using the industries 
resources. The mechanism of its action can be formulated as follows: in regarding to the majority of the population, a smaller share of the industry's resources becomes available, and additional resources become available to a small number of the chosen, improving the resource's provision only for a small number of the consumers of industry's goods.

Third, are the indicators of the resources using efficiency within the industries. Differentiation of the indicators of the population life quality between countries cannot be explained in case of ignoring the fundamental fact that different countries receive significantly different results in the life quality due to the using unit of resources amount, allocated to the certain sector of education and healthcare. Among the factors of such a difference we highlight a different share of administrative costs, unequal management efficiency, in particular, material incentives and ensuring the responsibility for quality of services, etc. Within our research, all this complex system of factors is taken into account as part of the integrated characteristic "the efficiency of industry's resources using".

We proceed from the assumption that the index of human development (HDI) may be considered as a quantitative measure of the social outcomes, gained by the education and healthcare. Such index reflects not only direct education and healthcare impact, but is dependent on indicators, which expresses impact of many other factors, more or less interconnected with state of affairs in social sphere. But the researched industries ability to meet the needs of population is a matter factor of HDI and its differentiation between countries in any case.

Accordingly, a function built on the data of a number of countries will reflect the generalized, universal characteristics of connection between social sphere resource endowment (as factor) and population life quality (expressed through IHD, as a dependent variable), and the rejection of individual countries from the general trend will express the specificity of their national structure of social sphere resources distribution and institutions, governing their use.
According to the above, we propose the following general model which expresses the resource, structural and institutional factors impact on the welfare of the population, measured by the index of human development.

$$
\begin{gathered}
H D I=\left(R e d u \_g o v \times K I e g\right)^{K E e d u \_g o v} \times \\
\left(R e d u \_p r \times K I e p\right)^{K E e d u \_p r} \times\left(R h c \_g o v \times K I h c g\right) \\
\text { KEhc_gov } \times\left(R h c \_p r \times K I h c p\right)^{K E h c \_p r} \quad(1),
\end{gathered}
$$

Redu_gov - amount of resources provided to public sector of education (public spending on education per capita);

KIeg - correction coefficient, expresses inequality of access to goods, provided by public sector of education;

KEedu_gov - coefficient expresses efficiently of using resources, provided to public sector of education;

Redu_pr - amount of resources provided to private sector of education (private spending on education per capita);

KIep - correction coefficient, expresses inequality of access to goods, provided by private sector of education;

$K E e d u \_p r-$ coefficient expresses efficiently of using resources, provided to private sector of education;

$R h c \_g o v$ - amount of resources provided to public sector of healthcare (public spending on healthcare per capita);

KIhcg - correction coefficient, expresses inequality of access to goods, provided by public sector of healthcare;

KEhc_gov - coefficient expresses efficiently of using resources, provided to public sector of healthcare;

$R h c \_p r$ - amount of resources provided to private sector of healthcare (private spending on healthcare per capita);

KIhcp - correction coefficient, expresses inequality of access to goods, provided by private sector of healthcare;

$K E h c_{-} p r$ - coefficient expresses efficiently of using resources, provided to private sector of healthcare.

Since the target indicator is aggregated, it means that dependent variable is influenced not only by average (per capita) spending but also 
by the share of population, which needs in educational and healthcare goods has been satisfied with using significantly smaller amount of resources, than may be expected by the average (per capita) indicators.

The coefficients "KI" (coefficient inequality) were included into model to reflect the influence of such inequality. The size of these coefficients varies from "0" to " 1 " and will be so closer to "0", the greater the inequality of access to the goods and services, provided by education and healthcare.

The group of indicators "KE", included in the model as coefficients of power, express the influence of a complex set of factors that are generally defined as "characteristics of resource efficiency" in the particular sector of social sphere. In the first approximation, this is an individual for each country a set of structural and institutional factors, which determine the various social outcomes per unit of resource endowment of education and healthcare.

The form of the function is analogous with widely used models, developed for reflecting the connection between the amount of resources (as a factor) and social outcomes obtained (as a dependent variable) through a log-linear equation [26; 27; 28; 29]

The World Bank data and the OECD statistics database on GDP in dollars for purchasing power parity and the size of public and private spending on education and medicine, expressed as a percentage of GDP were used to build a database.

Accordingly, the volume of resources of a particular sector (for example, the public sector of education) was defined as:

$$
R e d u \_g o v=G D P p p \times S H e d u \_g d p \_g o v,
$$

GDPpp - GDP per capita, in \$ by PPP;

SHedu_gdp_gov - public spending on education, expressed as share of GDP;

The national inequalities in life expectancy (for healthcare) and indices of inequality in the average number of years of education (for education) which are presented in human development reports were used as a measure of inequality in access to education and healthcare. Accordingly, the impact of the access inequality for the goods of education and healthcare was taken into account only in the first approximation - with the same coefficients for the private and public sectors of these industries:

$$
\begin{aligned}
& \text { KIedu }=(100-\text { Inequality in education }) / \\
& 100 \\
& \text { KIhc }=(100-\text { Inequality in life expectancy }) \\
& / 100
\end{aligned}
$$

This, of course, reduces the quality of the database used and requires an improvement of measure of the access inequality to the goods, proposed by education and medicine, in further research.

Consequently, the reduced (more convenient for further using) specification of our model may be presented as follows:

$$
H D I=a_{0} \times X_{1}{ }^{a 1} \times X_{2}{ }^{a 2} \times X_{3}{ }^{a 3} \times X_{4}{ }^{a 4},
$$

$a_{0}-$ coefficient for transformation of factor variables dimension into dimension of dependent variable;

$$
\begin{aligned}
& X_{1}=R e d u \_g o v \times K I e g \\
& a l=K E e d u \_g o v ; \\
& X_{2}=R e d u \_p r \times K I e p \\
& a 2=K E e d u \_p r \\
& X_{3}=R h c \_g o v \times K I h c g \\
& a 3=K E h c \_g o v ; \\
& X_{4}=R h c \_p r \times K I h c p ; \\
& a 4=K E h c \_p r
\end{aligned}
$$

Vectors of the actual values of the explanatory variables $(\mathrm{X} 1, \mathrm{X} 2, \mathrm{X} 3, \mathrm{X} 4)$ were formed according to the data of 28 countries (10 post-socialist countries, including Ukraine and 18 countries "old" OECD members) for 2016, or the last available year, using OECD statistics and World bank statistical database.

Parameters a0, $a_{1}, a_{2}, a_{3}, a_{4}$ have been evaluated as results of modeling.

The composition of the sample is due to the availability of data and to the relevance for comparative analysis of the connection between social sphere's resources endowment and the results of its functioning in the developed countries and countries that relatively recently began the formation of market mechanisms for meeting the population's needs in the goods of education and healthcare. 


\subsection{Conducting research and results}

To evaluate parameters of the model, we took logarithm of both of its sides and expressed it in a linear form:

$$
\begin{gathered}
L n(H D I)=L N a_{0}+a_{1} * L N\left(X_{1}\right)+a_{2} * L N\left(X_{2}\right) \\
+a_{3} * L N\left(X_{3}\right)+a_{4} * L N\left(X_{4}\right), \quad(4)
\end{gathered}
$$

This form of presentation allows using LSM and matrix calculations to define the vector of model parameter estimates, which was used in the built-in functions of the Excel package.

In the matrix form, the vector of the estimated model parameters looks as follows:

$$
A=\left(X^{*} X\right)^{-1}\left(X^{*} Y\right),
$$

$\mathrm{X}$ - matrix of explaining variables;

$\mathrm{X}^{*}-$ transposed matrix of explaining variables;

$\mathrm{Y}$ - matrix of dependent variable.

The results of estimation parameters of logarithmically linear function are given in the Table 1.

This model in the primary (nonlinear) form has a specification:

$$
\begin{gathered}
H D I^{*} 1000=6,093 \times X_{1}^{0,041} \times X_{2}^{0,0004} \times \\
X_{3}^{0,0388} \times X_{4}^{0,0122} .
\end{gathered}
$$

This function is sufficiently convenient for the interpretation of the estimates, since the coefficients of the power (evaluated by the LSM in linear form of model) reflect the partial elasticity of the dependent variable from the change of the corresponding factor.

Table 1

Results of modeling on 28 countries data

\begin{tabular}{|c|c|c|}
\hline Parameters & $\begin{array}{c}\text { Parameter's } \\
\text { estimate }\end{array}$ & t-statistic \\
\hline $\mathrm{a}_{0}$ & 6,093638 & 80,04366 \\
\hline $\mathrm{a}_{1}$ & 0,041069 & 2,339619 \\
\hline $\mathrm{a}_{2}$ & 0,000402 & 0,069249 \\
\hline $\mathrm{a}_{3}$ & 0,038866 & 2,794372 \\
\hline $\mathrm{a}_{4}$ & 0,012276 & 0,950479 \\
\hline $\mathrm{R}^{2}$ & \multicolumn{2}{|c|}{0,908} \\
\hline $\mathrm{F}$ & \multicolumn{2}{|c|}{57,105} \\
\hline
\end{tabular}

According to estimates obtained, the highest elasticity of HDI was recorded regarding to the public education expenditures corrected by the corresponding index access inequality (X1).
The HDI elasticity on the public healthcare spending (X3) - 0.0388, has second rate. The HDI elasticity on private healthcare expenditures is 0.0123 , and the estimation of the HDI elasticity on the private spending on education is clearly unreliable.

Accordingly with estimations of model parameters obtained, the differentiation of the HDI level within the sample is explained primarily by the differences in the size of public expenditure on education. The amounts of resources directed to the private and public sectors of healthcare were less significant for an explanation of fluctuations in the size of the HDI between countries.

The coefficient of HDI elasticity on scale (the sum of partial elasticity coefficients) according to the results of modeling is 0.0926 . That is, the increase of the total resources of education and healthcare by $1 \%$ causes an increase in the HDI of the country by an average of almost $0.1 \%$.

However, the reliability of the power coefficients in our model was not high: $t$ statistic is the higher than normative value for parameters a1 and a3 (those that describe the response of the HDI to changes in the financing of the budget sectors of education and healthcare $-\mathrm{X} 1$ and X3). But estimates obtained for both private sectors (a2 and a4) cannot be considered as reliable.

The using of the panel database allow us to suggest that the causes for this low reliability of the estimates obtained is not related to the phenomenon of residual auto-correlation (it is more typical of models based on dynamic series data). Therefore, we do not quote the value of the Darbin-Watson coefficient that was close enough to the value of "2" for the our model residuals.

However, the four variables presence in the model causes the possibility of distorting the coefficients' estimates (redistribution of the influence importance between the variables, included in the model) due to the phenomenon of multicollinearity.

The relevance of this problem for our model follows from the fact that the volume of budgetary expenditures on education and healthcare, although competing within the 
national budgets (under the condition that total budget size is considered as a constant), but both positively correlate with the total volume of budget expenditures. The last fact caused by direct connection between total government activity (measured by total budget spending) and spending on healthcare and education, evidenced by many researches (see for example $[22 ; 27 ; 30])$. Accordingly, variation of the educational and healthcare spending between the countries is likely to be influenced by the fluctuations of the common third variable, which is not included in the model: the total budget expenditures.

Similarly, private spending on education and healthcare, although competing within the consumer budget, however (as normal good with positive income elasticity) positively correlates with the overall size of the consumer budget. Accordingly, the fluctuations of private spending on education and healthcare between countries are likely bot influenced by overall size of consumer budgets.

The verification of the formed database upon criterion of explicit multicollinearity of factor variables has identified the existence of this problem (the matrix of correlation coefficients is given in Table 2).

The determinant of the correlation matrix is much closer to zero than to one $(0.067)$, which indicates the pronounced presence of multicollinearity. The cause of such a phenomenon is the affinity, inherent to fluctuations between countries of variables X1 and $\mathrm{X} 3$ - the correlation coefficient is 0.78 . As well as the parameters $\mathrm{X} 3$ and $\mathrm{X} 4$ - the correlation coefficient is 0.77 .

Table 2

The cross-correlation matrix of factor variables

\begin{tabular}{|c|c|c|c|c|}
\hline & $\mathbf{X 1}$ & $\mathbf{X 2}$ & $\mathbf{X 3}$ & $\mathbf{X 4}$ \\
\hline $\mathbf{X 1}$ & 1 & 0,046428 & 0,781893 & 0,558711 \\
\hline $\mathbf{X 2}$ & 0,046428 & 1 & 0,499218 & 0,494062 \\
\hline $\mathbf{X 3}$ & 0,781893 & 0,499218 & 1 & 0,772151 \\
\hline $\mathbf{X 4}$ & 0,558711 & 0,494062 & 0,772151 & 1 \\
\hline
\end{tabular}

A similar situation is observed by dividing the general sample into two groups of countries: the "old" members of the OECD and the postsocialist countries. Both models built on isolated databases of OECD and "post-socialist" countries retain rather high determination coefficient (0.969 for the post-socialist model and 0.838 for the old OECD members), and the Fisher coefficients, which are significantly higher than normative. However, t-statistics of parameters' estimates are less than the standard size for three of the four variables included in the models. Reliable assessment has been obtained only with regard to the coefficient of power for the variable "Adjusted for the access inequality public health expenditures" - for post-socialist countries and for the variable "adjusted for the access inequality budget expenditures on education" - for "old »Members of the OECD (tables 3 and 4).

The phenomenon of multicollinearity is the cause of such low reliability of the parameters' estimates also as in the model on the data of all countries. For the model, built on data of the "old" OECD countries, the phenomenon of auto-correlation of factor variables is somewhat weaker (the correlation matrix determinant 0.155 versus 0.0546 for post-socialist countries). The strongest correlation is observed between private and public expenditures within the healthcare sector. Private and public expenditures on education are related less and have interacted more as substitutes than as complementary components of total expenditure. The total amount of education sector's resource endowment in the postsocialist countries is not sufficient for the appearance of substitution effect between private and public expenditures.

Table 3

Results of modeling on 10 post-socialist countries data

\begin{tabular}{|c|c|c|}
\hline Parameters & $\begin{array}{c}\text { Parameter's } \\
\text { estimate }\end{array}$ & t-statistic \\
\hline $\mathrm{a}_{0}$ & 6.146942 & 39.1214 \\
\hline $\mathrm{a}_{1}$ & -0.0546 & -0.80374 \\
\hline $\mathrm{a}_{2}$ & 0.031635 & 1.872427 \\
\hline $\mathrm{a}_{3}$ & 0.087715 & 3.402361 \\
\hline $\mathrm{a}_{4}$ & 0.034914 & 1.550776 \\
\hline $\mathrm{R}^{2}$ & \multicolumn{2}{|c|}{0.969} \\
\hline $\mathrm{F}$ & \multicolumn{2}{|c|}{39.18} \\
\hline
\end{tabular}

We have tried to eliminate phenomenon of multicollinearity, removing from the model the variable, which, according to the correlation matrix indicators, creates the strongest 
autocorrelation. According to the results of our calculations, this is $\mathrm{X} 3$ (adjusted public expenditures on healthcare), which correlates strongly with both X1 (adjusted public expenditures on education) and X4 (adjusted private healthcare expenditures).

Estimates of model parameters with three factor variables are given in Table 5.

For data by all sample countries, we were able to obtain meaningful estimates of the two coefficients of power (X1 and X4). The same parameters could be reliably estimated according to the model on sample includes "old" OECD members. According to the model, built on data of post-socialist countries, only the estimation of the power coefficient for variable $\mathrm{X} 1$ is reliable (according to estimates of $\mathrm{t}-$ statistics).

Table 4

Results of modeling on 18 "old" OECD members data

\begin{tabular}{|c|c|c|}
\hline Parameters & $\begin{array}{c}\text { Parameter's } \\
\text { estimate }\end{array}$ & t-statistic \\
\hline $\mathrm{a}_{0}$ & 6.016512 & 49.39174 \\
\hline $\mathrm{a}_{1}$ & 0.050617 & 2.030695 \\
\hline $\mathrm{a}_{2}$ & 0.003056 & 0.396256 \\
\hline $\mathrm{a}_{3}$ & 0.032456 & 1.187543 \\
\hline $\mathrm{a}_{4}$ & 0.017923 & 0.906058 \\
\hline $\mathrm{R}^{2}$ & \multicolumn{2}{|c|}{0.838} \\
\hline $\mathrm{F}$ & \multicolumn{2}{|c|}{16.83} \\
\hline
\end{tabular}

Table 5

Results of modeling on 28 countries data with free variables

\begin{tabular}{|c|c|c|}
\hline Parameters & $\begin{array}{c}\text { Parameter's } \\
\text { estimate }\end{array}$ & t-statistic \\
\hline $\mathrm{a}_{0}$ & 5.955623 & 90.73448 \\
\hline $\mathrm{a}_{1}$ & 0.080061 & 6.634663 \\
\hline $\mathrm{a}_{2}$ & 0.007751 & 1.319977 \\
\hline $\mathrm{a}_{4}$ & 0.028919 & 2.227106 \\
\hline $\mathrm{R}^{2}$ & \multicolumn{2}{|c|}{0.877} \\
\hline $\mathrm{F}$ & \multicolumn{2}{|c|}{57.29} \\
\hline
\end{tabular}

Accordingly, the results we have received do not allow us to consider quantitative estimates of the HDIs elasticity on the volume of financial resources allocated to the private and public sectors of education and healthcare as reliable. But we have obtained grounds to assert about presence some nonrandom ratios between them.

In particular, we can assume as reliable thesis about the most significant impact of the resources, allocated to the public sector of education as a factor, influencing the country's achievement of HDI. Amount of resources, allocated to the private sector of education and both sector oh healthcare have the less pronounced impact on country's position among member of sample upon criterion of HDI.

We also received empirical evidence that in post-socialist countries (in which the GDP per capita and the resource endowment of education and healthcare are generally lower, compared with countries "old" OECD members), the achievements regarding the size of the HDI are more dependent on the amount of social sphere resources. Thus, according to the four-factor model on the database of post-socialist countries, the sum of three non-negative power coefficients (expresses scale effect for three sectors of the social sphere) is equal to 0.154 . And according to the analogous model on data of countries "old" members of the OECD, the sum of four non-negative power coefficients (scale effect for all four sectors of the social sphere) is equal only 0.104 .

Such results correspond to the theoretical view of the income's "diminishing marginal utility" (for short-term models) and the "diminishing scale impact" (for long-term): with the growth of GDP per capita and the expansion of social sphere's resource endowment, certain improvement in the life quality requires more and larger additional increments of resources, which will be allocated for education and healthcare.

However, this thesis is not proofed by the data of Ukraine.

So, if indeed, the growth of a GDP per capita is accompanied by a declining return on the growth of social sphere's resources, then for Ukraine (which has the smallest GDP per capita and also smallest size of social sphere's all sectors resource endowment), the excess of dependent variable's real value over calculated by model should be observed. However, the actual level of HDI in Ukraine is lower than 
estimated. This means that, given the actual size of social sphere's resources and compliance with the average level of its using efficiency, Ukraine should receive more value of the HDI than it actually has. In essence, the excess of the estimated value of the HDI for Ukraine over the actual testifies to the under-utilizing the existing resource potential of the social sphere: Ukraine uses resource of its social sphere with lower efficiency, than observed as average for countries, included in the sample.

This can be interpreted as a sign of problems with the quality of institutions regulating the resources using in social sphere, both in the private and public sectors. In particular, in our previous studies, we have already noticed that, in terms of one dollar by PPP, which is spent on funding of education and health care in Ukraine, society succeeds to provide significantly lower salary of employees in the sector (teachers and doctors), than many developed countries. We emphasize, it is not a question of comparing the absolute earnings of employees in these industries in Ukraine and other countries (this differentiation is traditionally explained by the incomparably smaller resources of the social sphere in Ukraine). According to our estimates, even a unit of resources, allocated to the social sphere is used in Ukraine with less effectiveness than in many developed countries, upon to the criterion of the salaries of teachers and doctors, per unit of volume of education and healthcare financing.

For example, according to our calculations, "... in every dollar that society pays for the functioning of the public health care system, in Mexico it is possible to pay almost 16 times more money as wages of doctors than in Ukraine. This is a direct sign of the extremely low comparative effectiveness of the government institutions in Ukraine. Thus, in Estonia, there is threefold surplus of state health care resources (per capita) allows to pay to physician more than 19 times higher salaries than in Ukraine. In other words, the effectiveness of using public funds by officials in Estonia exceeds the Ukrainian by almost six times.
In Hungary, every dollar per capita that government directs in the public healthcare sector allows to pay 6.7 times higher earnings to doctors than in Ukraine, in Mexico - 15 times, in Turkey -8.5 times » ([27, p. 38]).

Accordingly, it is precisely the clarification of the public sectors' of education and healthcare characteristics and comparison them in post-socialist and developed countries, we consider as a promising direction for further research. We plan to find out the critical differences inherent Ukraine comparing with the developed countries upon criterions the structure of distribution and the norms of using resources, allocated to the leading sectors of the social sphere. It would to allow clarify the directions of their reforms and ways for approaching Ukraine to developed countries on the criterion of the effectiveness of utilization an investment in human capital in the social sphere.

\section{Conclusion}

1. We can assume as reliable thesis about the most significant impact of the resources, allocated to the public sector of education as a factor, influencing the country's achievement of HDI. Amount of resources, allocated to the private sector of education and both sector oh healthcare have the less pronounced impact on country's position among member of sample upon criterion of HDI.

2. We also received empirical evidence that in post-socialist countries (in which the GDP per capita and the resource endowment of education and healthcare are generally lower, compared with countries "old" OECD members), the achievements regarding the size of the HDI are more dependent on the amount of social sphere resources. Thus, according to the four-factor model on the database of postsocialist countries, the sum of three nonnegative power coefficients (expresses scale effect for three sectors of the social sphere) is equal to 0.154 . And according to the analogous model on data of countries "old" members of the OECD, the sum of four non-negative power coefficients (scale effect for all four sectors of the social sphere) is equal only 0.104 . 
3. The actual level of HDI in Ukraine is lower than estimated by model averaged for countries, included in the sample. This means that, given the actual size of social sphere's resources and compliance with the average level of its using efficiency, Ukraine should receive more value of the HDI than it actually has. The mentioned excess of the estimated value of the HDI for Ukraine over the actual testifies to the under-utilizing the existing resource potential of the social sphere: Ukraine uses resource of its social sphere with lower efficiency, than observed as average for countries, included in the sample. This can be interpreted as a sign of problems with the quality of institutions regulating the resources using in social sphere, both in the private and public sectors.

4. We tend to consider the way to increase the social efficiency of utilization the investments in human capital in education and healthcare industries as promising direction of further research. We will go beyond the information base provided by the human development index and its components. The data on the average and expected duration of training, as well as the expected life expectancy at birth are under the influence of too large a set of factors to provide meaningful information on the causes of low effectiveness of resource using in Ukrainian social sphere. We plan to make a decomposition of the target for a range of instrumental characteristics of the education and healthcare functioning in order to find out how to overcome Ukrainian lagging in effectiveness of using social sphere resource for improvement population's life quality.

\section{References:}

[1] Human Development Report 2019. Beyond income, beyond averages, beyond today: Inequalities in human development in the $21 \mathrm{st}$ century. UNDP. 2019.

[2] Barro, R. (2001). Human capital and growth. American Economic Review 91, 1217.10.1257/aer.91.2.12

[3] Somé1 J., Pasali S. \& Kaboine M. (2019). Exploring the Impact of Healthcare on Economic Growth in Africa. Applied Economics and Finance Vol. 6, No. 3; May 2019. doi:10.11114/aef.v6i3.4110
[4] Bedir S. (2016). Healthcare Expenditure and Economic Growth in Developing Countries. Advances in Economics and Business 4(2): 76-86.

[5] Human Development Report 2013. The rise of South. UNDP. 2013.

[6] Abdurazakov, A., A. Minsat and J. Pineda (2013). Implications of Education Policies in a Country's Demographic Prospects: Detailed Analysis of Demographic Trends Based on Projections by Lutz and KC. Human Development Research Paper. United Nations Development Program, Human Development Report, New York.

[7] Abe, M. (2006). The Developmental State and Educational Advance in East Asia. Educate 6 (1), 6-12.

[8] Agbor, J. (2012). Op-Ed: Poverty, Inequality and Africa's Education Crisis. Brookings Institution, Washington, DC. Retrived 25 November 2018 from

http://www.brookings.edu/opinions/povertyinequality-andafricas-education-crisis/

[9] Bao G., Zeng F., Wang M. (2020). Study on Human Resource Allocation Efficiency Based on DEA Analysis, International Journal of Circuits, Systems and Signal Processing, pp. 826-832, Volume 14.

[10] Junjie L., Cai D., Zhu D., Huang S. (2020). A Regional Industry Intelligence Business Platform based on Adaptive Clustering, International Journal of Circuits, Systems and Signal Processing, pp. 656-660, Volume 14.

[11] Park S. Revisiting Mankiw, Romer \& Weil (1992), A Contribution to the Empirics of Economic Growth, University of Michigan, Retrived 25 November 2018 from http://141.211.177.75/econ/detail/0,2484,16060 \%255Fpeople\%255Fecon 105,00.html

[12] Mankiw, N. G., Romer, D., \& Weil, D. N. (1992). A Contribution to the Empirics of Economic Growth. The Quarterly Journal of Economics, 107(2), 407-437. doi: $10.2307 / 2118477$.

[13] [Mehlum H., Moene K.O. and Torvik R. (2005) Institutions and the Resource Curse. Economic Journal, 116, 1-20.

[14] Bilenko, Y. (2013), Dynamic economic effects of EU membership for post socialist countries of Central and Eastern Europe. Wroclaw Review of Law, Administration \& Economics, 3 (1), 90-103.

[15] Pietrzak, M. B., Balcerzak, A. P., Gajdos, A. and Arendt, Ł. (2017). Entrepreneurial environment at regional level: the case of Polish path towards sustainable socio-economic development. Entrepreneurship and 
Sustainability Issues, 5(2). 190-203, doi: 10.9770/jesi.2017.5.2(2).

[16] Balcerzak, A. P., \& Pietrzak, M.B. (2016). Quality of Institutions for Knowledge-based Economy within New Institutional Economics Framework. Multiple Criteria Decision Analysis for European Countries in the Years 2000-2013. Economics \& Sociology, 9(4), 66-81. DOI: 10.14254/2071-789X.2016/9-4/4.

[17] Stier, K. (1993). "Thailand Caught Between Economic Levels". Los-Angeles Times. (November 8).

[18] Behabib J., \& Spiegel M.M. (October 94). “The Role of Human Capital in Economic Development: evidence from Aggregate CrossCountry Data". Journal of Monetary Economics. 34, 143 - 161.

[19] Hanushek E.A. "Interpreting recent research on Schooling in developing countries" World Bank Research Observer. 10. (August 1995, p. $230-$ 244).

[20] Cochrane, S.H. (1979). Fertility and education: What do we really know? Baltimore: John Hopkins University Press.

[21] OECD (2010). Health care systems: Getting more value for money. OECD Economics Department Policy Notes, No. 2.

[22] Batare S. (2012). Efficiency of Public Spending on Education. Public Policy And Administration, 11 (2), 171-186.

[23] AHRQ Research to Reduce Cost and Improve the Quality of Health Care. Content last reviewed April 2015. Agency for Healthcare Research and Quality, Rockville, MD. Retrived $25 \quad$ November 2018 from http://www.ahrq.gov/research/findings/factsheet s/costs/costqual/index.html

[24] Mamatova T.V., Chykarenko I.A., Moroz E.G., Yepifanova I.Y., Kudlaieva N.V. Management of enterprises and organizations under the conditions of sustainable development. International Journal of Management, 11(4), 2020, pp. 151-159

[25] Heyets V., Voynarenko M., Dzhedzhula V., Yepifanova I. \& Trocikowski T. (2021) Models and strategies for financing innovative energy saving activities, IOP Conf. Series: Earth and Environmental Science, 628, 012004, doi:10.1088/1755-1315/628/1/012004.

[26] Siddique,H.M., Mohey-ud-din, G., Kiani, A. (2019). Health, Education and Economic Growth Nexus: Evidence from Middle Income Countries Global Social Sciences Review (GSSR) Vol. III, No. IV (Fall 2018) Page: 68 86
[27] Asghar, N. Awan, A. and Ur Rehman, H., (2012). Human Capital and Economic Growth in Pakistan: A Cointegration and Causality Analysis. International Journal of Economics and Finance, 4(4), pp. 135-147.

[28] Cetin M., Dogan I. (2015). The impact of education and health on economic growth: evidence from Romania (1980-2011). Romanian Journal of Economic Forecasting - XVIII (2)

[29] Voynarenko M., Hurochkina V., Sushkova O., Yepifanova I. (2021) Beneficial ownership chain and its evaluation arrangement. Estudios de Economia Aplicada, 38, 4. 3991

[30] Kudinova A., Verba D. (2014). The problems of Ukrainian social sphere: result of resource scarcity or inefficient government regulation? Ukraine: aspects of labor, 3, 34-42.

\section{Contribution of individual authors to the creation of a scientific article (ghostwriting policy)}

The formulation of research main idea, its initial hypothesis and setting of purpose and expecting results - Lyudmila Synyayeva

The literature analysis and distinguish the gap in current researches - Denys Verba, Iryna Verkhovod and Angelina Yarchuk.

The methodology defining, development of statistical tools - Denys Verba and Iryna Verkhovod.

The database collecting - Iryna Verkhovod and Angelina Yarchuk.

The conducting of calculations, interpretation of gained quantitative characteristics and formal verification of model parameters - Denys Verba, Iryna Verkhovod, Angelina Yarchuk and Denys Aleksandrov.

The formulation of conclusions, the general critical review of manuscript - Lyudmila Synyayeva and Denys Verba.

Compliance with the WSEAS journals requirements for the article's format - Denys Aleksandrov.

\section{Creative Commons Attribution License 4.0 (Attribution 4.0 International, CC BY 4.0)}

This article is published under the terms of the Creative Commons Attribution License 4.0 https://creativecommons.org/licenses/by/4.0/deed.en US 